\title{
The Impact of Discourse Marker Instruction on Fluency, Accuracy, and Complexity Improvement of Iranian Intermediate EFL Learners
}

\author{
Ghader Asadzadian ${ }^{1}$, Rashid Saad ${ }^{1} \&$ Fereshteh Asadzadian ${ }^{2}$ \\ ${ }^{1}$ Department of Education, UM University, Kuala Lumpur, Malaysia \\ ${ }^{2}$ Department of ELT, Ahar Branch, Islamic Azad University, Ahar, Iran \\ Correspondence: Ghader Asadzadian, Department of Education, UM University, Kuala Lumpur, Malaysia.
}

\author{
Received: March 24, 2017 Accepted: May 9, 2017 Online Published: July 26, 2017 \\ doi:10.5539/ijel.v7n5p152 URL: http://doi.org/10.5539/ijel.v7n5p152
}

\begin{abstract}
The purpose of the study was to investigate the impact of discourse marker (DM) instruction on fluency, accuracy, and complexity improvement of Iranian intermediate EFL learner's writing. To this aim, among the two hundred forth year English major learners in Dezful university, Iran, fifty of them who were in the intermediate level, based on the scoring system of the university, were recruited. They were given a topic to write before intervention. Then, the fifty participants passed through twenty-hour instruction on micro and macro DMs, based on Belles-Furtuno's (2004) classification of discourse markers. The mentioned classification included both sentential and supra sentential markers. In the process of explicit instruction (EI) of DMs, they were given various exercises and activities to apply DMs and learn the function and usage of these units and input flood (IF) was performed along with corrective feedback (CF) with the help of the teacher with their mistakes and misunderstandings of DMs. After intervention, they were given another topic to write to examine if EI+IF of DMs could help them improve fluency, accuracy, and complexity of their writing. To quantify the results the Wolfe-Quintero (1998) method was used and it was unveiled that all the three components of writing improved after intervention, which practically means instruction of DMs could enhance learner's writing in the three aspects. The findings can be used by teachers and syllabus designers to consider DMs as one of the most crucial components in writing courses.
\end{abstract}

Keywords: discourse markers, corrective feedback title, fluency, accuracy, complexity, explicit instruction, input flood

\section{Introduction}

According to Hillocks (2005) writing has always played an important and undeniable role in the process of teaching, especially when it comes to academic setting. Writing as a demanding and sophisticated task requires high level of familiarity and awareness of the target language to enable the writer to express his ideas through combination of words and be informative enough to the reader.

As Belles-Fortuno (2004) claimed having the above features need goof ties in both sentential and supra-sentential levels of the language being produced. Moreover, two levels of writing were defined by Gabrielatos (2002). The first stage is language level which includes vocabulary and grammar can be called the "micro level". However, the second stage is the layout, punctuation and method of organizing ideas or "macro level". He claimed that the second stage is mostly ignored or given little attention to. Hence, producing a coherent and well-connected writing is hard to be expected.

De la Fuente (2009) stated that writing should be organized in a clear structure to avoid any ambiguity in the reader's mind. Words, sentences and paragraphs should be linked in the way that can guide the reader to the point the writer is aiming at. Gabrielatos (2002) argued that to achieve the target beside comprehensive knowledge of grammatical semantic rules and conventions of a language, the learner should be taught how to design the layout and arrange ideas in logic and well-organized structures.

Discourse markers can aid writers significantly to reach the goal that De la Fuente (2009) stated and also to arrange the layout to be understandable to readers. Discourse markers (DMs) have been defined by different researchers. Schiffrin was one of the pioneers regarding DMs in linguistic research. She defined DMs as "sequentially dependent elements which bracket units of talk". Richard \& Schmidt (2002) believed that DMs 
connect two parts of discourse, but they have no contribution to the meaning of either. Fuller (2003) also claimed DMs are units which have no role in grammatical or semantic form of sentences they are used in. Rahimi (2011) argued that DMs can help speakers or writers to be fluent and meaningful in their production of language, either oral or written form.

Teaching explicitly can draw the learners' attention to the presented material and remind them the items while performing (Hernandez, 2008). It can make them more conscious and aware of the subject being taught. The more reflective the learners are, the more efficient they can be.

According to Ellis \& Sinclair (2003), when learners have better control over what they are learning, they can get better results and can be more successful. The learners selected to go through the intervention process are intermediate level, hence they are expected to have a clear mind set and be able to properly apply what they are taught in the instructional process.

During the intervention period, students are given a comprehensive knowledge of DMs and their functions. They are also provided lots of examples and supplementary exercises to learn these units and the practical way of applying them which is considered as a flood of input presented to learners (IF) (Hernandez, 2008).

In the process of EI and IF, students face some problems and make some mistakes which are corrected by the teacher directly. In the CF process, the mistakes are underlined and corrected by teacher to avoid any confusion or misunderstanding by learners. In other words, there is a process of EI+IF along with direct and focused CF (Ellis et al., 2008).

The three concepts that can have an enormous effect on the quality of writing are fluency, accuracy, and complexity. For the sake of minimizing mistakes and feeling secure, learners mostly try to shorten or simplify their writing (Taguchi, 2009). In case of shortening or simplifying their writing product, learners' writing might not be fluent, accurate, or complex enough.

Various linguistic levels, including phonology, morphology, syntax, semantics, discourse, and pragmatics can be taken into account while thinking of fluency, accuracy, and complexity. For instance, fluency measures how rapidly or easily discourse moves are executed, accuracy deals with the appropriateness of the moves in the context, and complexity investigates how varied the moves are (Wolfe-Quintero, Inagaki, \& Kim, 1998, p. 5).

Young (1994) stated that there are three types of comparisons when it comes to measuring aspects of language: comparison between developmental measures and proficiency measures in which developments of different proficiency levels are measured, comparison among proficiency measures in which progress of different proficiency levels are compared, and comparison among developmental measures in which development of the same level participants is measured in a certain time period.

In the case of proficiency measures, there might be learners with various abilities in oral versus literate modalities. For measures of language development, there might be writers who are accurate but not fluent or fluent but non-accurate, or writers with complex syntax but with lack of lexical complexity or the reverse (Hamp-Lyons, 2002).

According to what was mentioned above it is clear that there have been several works on DMs in different skills. But there have been few works on DMs in writing, particularly when EI+IF are included and there is a process of CF. Explicit instruction of DMs along with a process of input flooding seem to help learners understand the usage and function of DMs better. Along with these, corrective feedback on learners' answers to the exercises can help them enhance their understanding of the correct forms. These units are not taught in schools in Iran. I assume that is why most Iranian students' writings are full of short and choppy sentences and there is not clear and smooth connection in the whole writing. Therefore, the following research questions are answered to in the current study:

\section{Research Question 1}

Is there a significant difference in within experimental group in terms of fluency before and after the intervention?

\section{Research Question 2}

Is there a significant difference in within experimental group in terms of accuracy before and after the intervention?

\section{Research Question 3}

Is there a significant difference in within experimental group in terms of complexity before and after the 
instruction?

\section{Explicit Instruction, Input flood, and Corrective Feedback}

The effect of explicit instruction (EI) becomes more vivid in both researchers' work and empirical studies. Some researchers, including: Dekeyser (1995), Schmidt (1990; 1995; 2001), Alanen (1995), De Graaff (1997), Hernandez (2008) claimed that EI, which is defined as giving learners enough explicit knowledge and information about the target language structure during the learning process, facilitates learning the second language. Yoshimi (2001) worked on the effect of EI of DMs on using these units by Japanese learners. The results revealed that the group which enjoyed EI could use DMs better than the other group.

There is also the opposite party, who believe EI has no effect in the process of learning, including: Baneti (2004), Farely (2004), and Wong (2004). A study by Rosa \& O'Neil (1999) unveiled that EI has no effect on the experimental group and they did not outweigh the control group.

In the process of EI the concept of input flood (IF) has grabbed researchers' attention. It has found its meaning through combination of Frequency Hypothesis by Hatch \& Wanger-Gough (1976), Gass (1997) and Noticing Hypothesis by Schmidt (1990; 1995; 2001). As Wong (2005) stated, IF process includes familiarizing learners with the target item with the help of various examples and exercises. IF gives them the ability to use the target structure being instructed.

Mainly researchers believe that IF along with EI can help learners gain better understanding of usage of the item being taught, such as: Trahey \& White (1993), White (1998), and Williams \& Evans (1998). Hernandez (2008) studied two groups, one of which received EI+IF, while the other received just IF. The results revealed that the former group outweighed the latter in their usage of DMs.

However, there is a group of researchers who believe IF can have its effect and there is no need for EI Reinders \& Ellis (2009) studied two groups, one of which received EI+IF, while another one received only IF. The results illustrated that was no significant difference in the performance of the two groups. Therefore, they claimed that EI had no influence on learners' achievement.

Another concept in the process of EI is corrective feedback (CF). CF, as Ellis (2005) mentioned, is one of the ways to use focus-on-form instruction. With the help of CF in writing process, teachers can draw learners' attention to their mistakes and during intervention remove them. Whereas, in the other form of production, which is spoken language, $\mathrm{CF}$ is believed not to be as fruitful, because of interrupting learners and eventually cutting the communication flow. Polio, Fleck, \& Leder (1998) argued that in spoken language instruction should be delayed and feedback should be given after finishing communicating the meaning.

Orally provided CF has effect on correcting learners' mistakes, but it cannot be as much effective as it is in the written CF (Adams, 2003). Both modalities are aiming at removing students' mistakes and noticing the mismatch between the target language and the learners' inter-language system. However, in oral CF, learners' attention resources are limited (Schmidt, 2001). Hence, in writing, the learners are given the chance and they have enough time and cognitive resources, as Sheen (2010) noted, to notice the gap in their inter-language.

There are also some oppositions to CF. Truscott (1996) believed that teachers' ability to give the feedback and learners' willingness to receive it put a question mark on partiality of CF. Truscott (2004) also claimed that CF is just waste of time and can be replaced by other activities, like extra writing. Skehan (1998) believed that CF can end in conservative view towards language and learners might reduce the complexity level of their language for the sake of accuracy. While Robinson $(2003 ; 2005)$ claimed that complexity and accuracy are not two sides of the same coin. They can be closely connected and even complete each other.

There are two forms of CF, focused and unfocused. The advocates of focused CF, like Ellis et al. (2008), Sheen (2007), and Bitchner (2008), believed that due to limited processing capacity and disturbing the process of writing correction, it can be more helpful. While advocates of unfocused CF argue that focused form cannot and in complete accuracy and it can be used for some grammatical correctness, like Bruton (2009) and Ferris (2010).

\section{Accuracy, Fluency, and Complexity in Writing}

After analyzing the use of cohesive vocabulary, Crossley \& Mc Namara (2009) claimed that L2 writers make use of cohesive vocabulary less than L1 writers. Hence, the text produced by an L2 writer is less readable, comprehensible, and coherent comparing to the one by an L1 writer. L2 writers' texts are, therefore, more context-dependent, less abstract, and less ambiguous.

As Skehan $(1996 ; 1998)$ mentioned, the ultimate goal of learners in the process of language learning is achieving native-like ability. To this aim, fluency, accuracy, and complexity, which are considered as the three major 
dimensions or aspects of a language, are required to be strengthened. The focus of fluency is on primacy of meaning, while complexity and accuracy concern with the form. (Foster \& Skehan, 2001)

Skehan (1996) defined accuracy as “a learner's capacity to handle whatever level of inter-language complexity she has currently attained". The stage and elaboration of the underlying inter-language system is what she stated as what complexity relates to. She also described fluency as "concerns the learner's capacity to mobilize inter-language system to communicate meaning in real time".

One of the controversial issues concerning the three aspects which can influence the quality of writing could most probably be the tradeoff effect. Skehan (1996) argued the complication as a cause to prioritize an aspect due to limited processing capacity of learners. He proposed that the conflict is between accuracy and fluency, while Wendel (1997) claimed this tradeoff involves fluency and accuracy.

Regarding the above-mentioned claim Ellis \& Barkhuizen (2005) suggested "elaborated language" which can be described at two levels: first, cutting-edge development of the learner's language, which is not yet thoroughly automatic. And second, learner's full preparedness to utilize an extensive range of linguistic structures. They pinpointed that when learners are producing more fluent language, they are prioritizing meaning over form which practically means fluency over accuracy.

In a study by Naoko Taguchi (2009) it was revealed that instruction on some grammatical chunks as constituents of discourse could result in complexity improvement of the participants' spoken language, but as for the fluency part there was no significant change in their oral production.

Three types of calculation can be used to measure the three quality measurement procedures. The first one is frequency which is simply counting the number of words, clauses or T-units in writing to come up with a frequency number. The second is a ratio measure. In this measuring system presence of one type of unit is expressed as the percentage of another type, or one type is divided by the total number of comparable units. The third type is an index based on a formula that produces a numerical score.

As it goes in the realm of developmental measures for calculating fluency, accuracy, and complexity, there can be three methods of calculation as follows (Wolf-Quintro, Inagaki, \& Kim, 1998).

The first way is calculating a feature, structure, or unit through a simple frequency count. For instance, for coming to a frequency score the writer counts the number of words, clauses, or T-units. Owing to depending on other external factors such as the allocated time or the nature of the task, frequency measures are not very strongly dependable.

Placing some conceptual limits like rewriting a passage or describing a picture, or temporal limits like time limit on a composition, however, can increase the value of this system of measurement.

The second method of calculation is using ratio which is considered a more valid way. In this procedure the presence of one type of unit is considered as the representative of the percentage of another type of unit, or one type of unit is divided by the total number of comparable units, for instance error-free units per total number of units of the same type.

The ratio can be used for various purposes, for example the length of the given unit (e.g., words per clause, sentence, or T-unit), the rate of accuracy within a given unit (e.g., errors or error-free units per clause, sentence, or T-unit), or the complexity of a given unit (e.g., clauses per T-unit, or T-unit per sentences).

The third type of calculation which produces numerical scores is index based on a formula. The indices are used in the condition that either the features under study are a weighted hierarchy of complexity (e.g., Flahive \& Snow, 1980; Perkins, 1983), or the researcher tries to use a more complex formula to calculate a score (e.g., Bardovi-Harlig, 1992).

In a study by Asghar Salimi, Alireza Bonyadi, \& Atefe Asghari (2014) on sixty English learners in a language institute in Iran it was revealed that focus-formed instruction could enhance the learners' accuracy.

Rod Ellis \& Fangyuan Yuan (2004) worked on the effect of planning on writing narratives of ESL writers. They designed the three types of planning which include: pre-task planning, on-pressured on-line planning, and no planning. The experiment was done on forty-two Chinese learners.

The results of the study revealed that pre-task planning could have its effect on greater fluency and syntactic variety, while unpressured on-line planning could significantly improve the accuracy of the learners' writing.

In an almost similar study by Piri, Barati, \& Ketabi (2012) in an Iranian atmosphere it was revealed that fluency could improve significantly with pre-task planning, while accuracy and complexity did not show a significant 
change. They also claimed that on-line planning and pre-task plus on-line planning could have little influence on narrative writing of the forty-five EFL learners in their research.

\section{The Current Study}

As Gabrielatos (2002) mentioned working on layout and organizing ideas of the writer is an important part of writing which is not worked on as much as necessary. Hence, to achieve level of writing which is comprehensible and comparable to the one produced by L2 users, writers need to be well-equipped with the tools to be capable of producing that level of writing.

Rahimi (2011) noted that DMs are crucial component of communicative competence. It means they can help speakers and writer arrange their thoughts and ideas in a well-designed structure.

To this aim, explicit instruction of DMs to familiarize learners with function and usage of these units seems essential. They can help learners achieve their target in writing, which is writing as fluent, accurate, and complex as native users of English.

\section{Method}

\subsection{Participants}

Among 200 fourth year learners in Dezful, Iran fifty of them who were placed as intermediate level recruited. The criterion was scoring system of the university, the two hundred students were listed based on their scores, and then those who were scored between 60 and 79 were placed in intermediate group.

\subsection{Material}

University scoring system was used to be a criterion upon which intermediate level learners ware determined. The next material was discourse markers based on Belles-Furtuno (2004) classifications. The two tables of micro and macro markers were based were used to familiarize subjects with the use and function of DMs through EI and IF process. Lots of exercise including sentence marking, changing drills, cloze passage, and the like were applied to present the markers to the subjects in experimental group. Finally, the topics for writing were chosen from IELTS samples.

\subsection{Procedure}

Initially, two hundred fourth year EFL learners in Dezful, Iran were recruited to form the intended intermediate level subjects. They were ranked based on the scoring system of the university. Those who were scored above eighty percent were in high group, between sixty and seventy nine the intermediate, and below sixty were in low group. As it has been mentioned in this study the purpose was working on the intermediate level. Hence, the fifty intermediate level learners were selected. They were given a topic to write in 40 minutes prior to intervention of DMs. Then the intervention period started. An experienced teacher was hired to do the instruction. The researcher was just observing the process and the teacher and researcher discussed and exchanged ideas about the type of exercise and activities in the course. In other words, the researcher did not directly influence the process of instruction to avoid any bias or partial view towards the results.

Intervention period took five weeks and it was a twenty hour course. Afterwards, they were given another topic to write, in the time limit of 40 minutes.

Eventually, the group was given another topic to write. Fluency, accuracy, and complexity of their writing was calculated based on Wolfe-Quintero's method of calculation, to examine the possible influence of EI+IF along with CF of DMs on planning fluency, accuracy, and complexity of their writing before and after the intervention.

\section{Results}

\subsection{Results on Research Question 1}

To answer this question the experimental group was given a topic to write before the intervention period and after this period was given another topic to observe the plausible change in the fluency of their writing due to the instruction on DMs.

Fluency was calculated based on Wolf-Quintero (1998) in two aspects of frequency (table 1) and ratio (table 2). In this study, frequency was calculated based on the number of words in T-units and ratio was the number of words per T-units which were both considered as developmental process. The calculated mean, standard deviation, and dependent T-test were as illustrated below: 
Table 1. Results for fluency (frequency)

\begin{tabular}{llllll}
\hline & Mean & Std. Deviation & T & df & Sig. \\
\hline Pre-Writing & 188.04 & 6.65 & \multirow{2}{*}{20.46} & \multirow{2}{*}{49} & \multirow{2}{*}{0.001} \\
Post- Writing & 208.2 & 11.08 & & \\
\hline
\end{tabular}

Table 2. Results for fluency (ratio)

\begin{tabular}{llllll}
\hline & Mean & Std. Deviation & T & df & Sig. \\
\hline Pre-Writing & 10.85 & .81 & \multirow{2}{*}{4.22} & \multirow{2}{*}{49} & 0.001 \\
Post- Writing & 11.47 & .86 & & & \\
\hline
\end{tabular}

As it is shown in tables 1 and 2, there is a significant difference between the means before and after the instruction which rise from 188.04 to 208.2 for the frequency and 10.85 to 11.47 for the ratio. Considering standard deviation in the two tables, increasing from 6.65 to 11.08 and 0.81 to 0.86 for the frequency and ratio respectively, also show a significant upward change.

Based on the results of the dependent T-test before and after the intervention, 20.46 for frequency and 4.22 for ratio, with the degree of freedom (49) the calculated $\mathrm{P}$ value $(\mathrm{P}<0.001)$, the significance levels shows that after the intervention period, fluency of experimental group increased significantly in both frequency and ratio aspects. In other words teaching DMs could enhance the learners' writing fluency.

\subsection{Results on Research Question 2}

The same procedure for the previous question was applied to the current one as well. Pre writing and post writing results were being considered to reach the required destination. Two aspects of frequency and ratio, which were depicted in tables 3 and 4 respectively, were used. To quantify the findings for these two aspects Wolfe-Quintero (1998) way of calculation was used.

Accuracy in the frequency aspect was calculated by the number of correct connectors utilized by the experimental group before and after instruction. Accuracy in the ratio aspect was calculated based on the formula by Evolta et al. (1980) which is the following formula: (see Appendix A)

The two calculations are on the basis of developmental process. The calculated mean, standard deviation, and dependent T-test are as illustrated below:

Table 3. Results for accuracy (frequency)

\begin{tabular}{llllll}
\hline & Mean & Std. Deviation & $\mathrm{t}$ & Df & Sig. \\
\hline Pre-Writing & 4.76 & .82 & \multirow{2}{*}{18.76} & \multirow{2}{*}{49} & \multirow{2}{*}{0.001} \\
Post- Writing & 9.00 & 1.63 & & \\
\hline
\end{tabular}

Table 4. Results for accuracy (ratio)

\begin{tabular}{llllll}
\hline & Mean & Std. Deviation & $\mathrm{t}$ & Df & Sig. \\
\hline Pre-Writing & .0219 & .003 & \multirow{2}{*}{13.27} & \multirow{2}{*}{49} & 0.001 \\
Post- Writing & .0363 & .007 & & & \\
\hline
\end{tabular}

Table 3 shows that the mean in frequency aspect changed from 4.76 to 9.00 after intervention and standard deviation from 0.82 to 1.63 . It shows that there is an upward trend in the results.

The result of the dependent T-test (18.76) with the degree of freedom (49), the calculated $\mathrm{P}$ value $(\mathrm{P}<0.001)$, the significance levels shows that after intervention, accuracy of the learners' writing increased significantly in frequency aspect.

Besides, as it is shown in table 4 in ratio aspect the mean changed from 0.0219 to 0.0363 and the standard deviation from 0.003 to 0.007 , before and after the instruction.

The results of the dependent T-test (13.27) with the degree of freedom (49), and the $\mathrm{P}$ value $(\mathrm{P}<0.001)$, the significance levels clarifies that the learners' writings showed an increase in their ratio aspect.

In brief, teaching DMs could enhance the learners' writing accuracy after instruction, in other words learners used these units to write more accurately. 


\subsection{Results on Research Question 3}

Following the same procedure, for calculating complexity two aspects of frequency and ratio were being considered which can be seen in tables 5 and 6 . To this end, pre-writing and post-writing of the learners were being investigated, like the previous questions about the experimental group. The method of calculation is based on Wolfe-Quintero (1998).

Based on Wolfe-Quintero (1998) complexity in frequency aspect was calculated by the number of connectors of all types which is the same way with what was introduced for measuring accuracy. Hence, the results would be the same, while complexity in ratio aspect is calculated by the number of T-units per sentences in pre-writing and post-writing of students. The calculations are based on developmental process. The results for mean, standard deviation, and dependent T-test are as illustrated below:

Table 5. Results for complexity (frequency)

\begin{tabular}{llllll}
\hline & Mean & Std. Deviation & T & Df & Sig. \\
\hline Pre-Writing & 4.95 & .82 & \multirow{2}{*}{19.7} & \multirow{2}{*}{49} & \multirow{2}{*}{0.001} \\
Post- Writing & 9.10 & 1.72 & & \\
\hline
\end{tabular}

Table 6. Results for complexity (ratio)

\begin{tabular}{llllll}
\hline & Mean & Std. Deviation & T & Df & Sig. \\
\hline Pre-Writing & 1.06 & .059 & \multirow{2}{*}{15.05} & \multirow{2}{*}{49} & \multirow{2}{*}{0.001} \\
Post- Writing & 1.29 & .084 & & & \\
\hline
\end{tabular}

As depicted in table 5 the calculated mean and standard deviation in frequency aspect in pre writing were 4.95 and 0.82 respectively. While after intervention the mean rose to 9.10 and the standard deviation to 1.72 , both of which show a significant increase.

The result of the dependent T-test (19.7) with the degree of freedom (49), the calculated $\mathrm{P}$ value $(\mathrm{P}<0.001)$, the significance levels shows that after intervention complexity level in frequency aspect had a significant increase. In other words, intervention period could increase learners' writing complexity. Table 6 shows that in ratio aspect the mean changed from 1.06 to 1.29 and the standard deviation from 0.059 before to 0.84 after intervention. It reveals that there is a significant difference in these two measures before and after instruction.

As for the dependent T-test with the value of 15.05 , the degree of freedom (49), and the $\mathrm{P}$ value $(\mathrm{P}<0.001)$ the significance levels shows that learners' writing experienced a significant improvement before and after intervention.

In sum, it can be claimed the findings of the current study clarify that in both aspects of frequency and ratio, learners' complexity of writing enhanced which practically means the instruction period could be beneficial for learners' writing complexity.

\section{Discussions}

\subsection{Discussions on Research Question 1}

In a study by Sato \& Lyster (2012) on Japanese learners it was revealed that peer interaction could increase learners' fluency, while form-focused CF could be helpful in both fluency and accuracy of their speaking.

The results of the current study also shows that form -focused CF could improve learners' fluency which means form-focused CF can be influential in learning process, as Ellis (2008) and Bitchner (2008) also confirmed it.

In the above study 167 Japanese students were divided into 4 groups among which 2 groups received CF, one group was just in peer interaction atmosphere, and one was the control group. The results clarified that peer-interaction-only group out-performed the control one in fluency, while the two groups that received form-focused CF could perform better in both fluency and accuracy aspects.

The results of this study reveal that learners' had not been taught on DMs properly, owing to the fact that they could outperform in their post writing in fluency aspect which shows that teachers' lack of awareness of the use and importance of these units could have been the root of the complication. Similarly, Rezvani (2012) performed a study on Iranian teachers. The results declared that teachers were moderately aware of the importance and role of these units. Therefore, it can be concluded that these units are necessary to be taught explicitly. 
Sabry \& Khaled (2013) studied writings of fifty Saudi learners in Qassim University and the results announced that students overused the DMs they knew and applied choppy and immature manner due to not using DMs. Besides they claimed that to improve writing fluency of learners, DMs should be taught. Findings of this study also confirm their claim, owing to the fact after instruction of DMs writing fluency of learners could improve, in other words teaching these units explicitly can enhance learners' writing fluency.

Opposing to a study by Taguchi (2009) findings of this study showed that learners utilized instruction on DMs to improve fluency of their writings. Taguchi (2009) conducted a research on twenty-two subjects who registered for Japanese course in the US. The results unveiled that they improved in complexity of their speech, while the results of their fluency did not show a significant change.

The twenty-two subjects were taught some grammatical chunks. After the intervention, they were tested and the results declared that the participants used the presented knowledge to monitor their language and enhance complexity of their speech, but not fluency.

Hence, the researcher claimed that learners use the instructed material to enhance complexity and monitoring power, while it cannot have impact on their fluency. The results of his work are in accordance with what Skehan (1996) claimed, while the results of the current study clarified that ,in opposition to what they argued, learners' fluency could improve significantly after intervention, which practically means they used the presented material to enhance their fluency. That is to say, explicit instruction has impact on enhancing fluency of writing.

\subsection{Discussions on Research Question 2}

Skehan (1996) defined accuracy as the ability of learners to apply the inter language complexity she has received. Likewise, in the current work; accuracy of writing product of learners is discussed based on DMs usage before and after instruction. The results show a significant change which practically means learners' writing accuracy could improve owing to interventional period on DMs. That is to claim learners were capable of applying the received information.

The current work was focusing on DMs as items which could possibly enhance learners' writing. Therefore, it is considered as a form-focused intervention, and results are in accordance with the study by Salimi, Bonyadi, \& Asghari (2014) which revealed that instruction with focusing on a certain form could improve learners' writing accuracy.

Their study on sixty Iranian learners in two high and low groups, each with one experimental and one control group, unveiled that after intervention, the experimental groups could outperform the control ones in their writing accuracy. Similarly, the current work showed that the experimental group could improve in accuracy after the instruction, comparing to what the performed before receiving explicit instruction.

In the current study, DMs were the focus of the intervention period which made it a direct corrective feedback that focused on these units only, and the results revealed that the focus could lead to enhancing learners' writing accuracy which confirms the study by Ahmadi-Azad (2014) which was done on fifty-four per-intermediate Iranian learners. In this study the researcher labeled CF as coded and un-coded ones by which she meant direct and indirect CF. The results after the instructional period on 10 kinds of errors, which were the main focus for the coded group, illustrated that direct or coded feedback could result in improving accuracy in learners' writing, while the indirect or un-coded one could not play the same role and could not make a significant change in the learners' writing accuracy.

In the current work, during the intervention period, the learners were discussing and working together collaboratively and trying to use the appropriate DMs and get help from others and also their teacher. Hence it could be considered a collaborative work with instruction and observation of the teacher who was giving the necessary help on these units' usage and function.

The results showed that writing accuracy could increase consequently. The study by Jafari (2012) on sixty Iranian EFL learners revealed that a collaborative work on writing could improve writing accuracy of learners, which is in accordance with the results of the current study. She attempted to provide the learners in experimental group a collaborative atmosphere, while the control group did not enjoy the same setting. Eventually, the findings revealed that the experimental group outperformed the control one in applying error-free T-units, which she interpreted as the positive impact of collaboration of learners on accuracy improvement. Correspondingly, findings of the current work confirm her results that with the help of collaboration accuracy of writing could improve. However, collaboration was not the sole key factor in this study. 


\subsection{Discussions on Research Question 3}

Wolfe-Quintero, Inagaki, \& Kim (1998, p. 5) noted that complexity investigates how varied discourse moves are. Therefore, regarding this view the number of connectors in frequency aspect and also the number of T-units in ratio can picture variety of discourse moves. In other words, the more of these components are used, the higher complexity of the text can be. Following the above definition, in both aspects of frequency and ratio, the writers show a significant improvement, hence it can be claimed that DMs and their explicit instruction could enhance complexity of learners' writings.

Truscott $(2004 ; 2007)$ claimed that CF is just a waste of time due to not having any significant influence on improving learners' knowledge and performance. He discussed that $\mathrm{CF}$ can be replaced by more beneficial activities, while Robinson $(2003 ; 2006)$ held the opposite opinion. He stated that CF can help complexity and accuracy. Truscott announced that his work revealed CF can end in a conservative view of the learners whose effort would be sacrificing complexity for the sake of accuracy.

Oppositely, the findings of this work conflict what he claimed. In other words, learners in the current work showed a significant change in their writing accuracy. Moreover, they presented a more complex text, which is in accordance with Robinson's belief that accuracy and complexity can be considered as two sides of a coin, they can be kind of complementary to each other which practically means the presence of accuracy cannot necessitate elimination of complexity. Considering the results of the current study, if learners are provided with enough input while being taught, they do not necessarily need to simplify their writing product to be assured of the accuracy of their work, as Truscott claimed to be so.

Naoko Taguchi (2009) studied twenty-two Japanese subjects. In his work he taught some grammatical chunks to the group and concluded that their complexity of speech could increase as a result of instruction. The findings of the current work also revealed that learners could improve complexity of their writing after interventional period on DMs which means it confirms what he claimed about the impact of EI on enhancing complexity.

\section{Conclusion}

In conclusion, explicit instruction of discourse markers along with input flood and corrective feedback can have positive impact on fluency, accuracy, and complexity of learners' writings in both frequency and ratio aspects. The results of the current work revealed that all the three aspects of writing could show a significant change as result of EI+IF along with CF. The findings can help teachers, in the process of their writing courses, and syllabus designers and curriculum planners, in their course plans.

\section{Suggestions for Further Research}

Due to the limitations of the current work, there are some suggestions for further study. This research included a small group of learners; therefore, larger groups may produce different results. Furthermore, age and gender as variables were not controlled in the current study. Another controlled variable was level of learners which was intermediate; other levels may produce different results. Last but not least, EI and IF were included, while one of them might have the same effect. All the above mentioned limitations could be considered as factors which could influence the results. Therefore, studying these elements can be topics for further researches.

\section{References}

Adams, R. (2003). $\mathrm{L}_{2}$ output, reformulation and noticing: implications for IL development. Language Teaching Research, 7(3), 347-376. https://doi.org/10.1191/13621688031r127oa

Alanen, R. (1995). Input enhancement and role presentation in second language acquisition. In R. Schmidt (Ed.), Attention and awareness in foreign language learning (pp. 259-302). Honolulu, HI: University of Hawaii Press.

Asghari, A., Bonyadi, A. R., \& Salimi, A. (2014). The effect of focus on form on EFL learners' written task accuracy across different proficiency levels. Theory and Practice in Language Studies, 4(4), 829-838.

Barati, H., Ketabi, S., \& Piri, F. (2012). The effects of pre-task, on-line, and both pre-task and on-line planning on fluency, complexity, and accuracy. The case of Iranian EFL learners' written production. English Language Teaching, 5(6), 158-167.

Bardovi-Harlig, K. (1992). A second look at T-unit analysis: Reconsidering the sentence. TESOL Quarterly, 26, 390-395. https://doi.org/10.2307/3587016

Barkhuizen, G., \& Ellis, R. (2005). Analyzing learner language. Oxford: Oxford University Press.

Belles-Fortuno, B. (2004). The spoken academic discourse of the social sciences. Discourse markers within the 
university lecture genre. Unpublished MA thesis. Castello: Universitat Jaume I.

Benati, A. (2004). The effects of structured input activities and explicit information on the acquisition of Italian tense. In B. VanPatten (Ed.), Processing instruction: Theory, research, and commentary (pp. 207-225). Mahwah, NJ: Lawrence Erlbaum.

Bitchener, J. (2008). Evidence in support of written corrective feedback. Journal of Second Language Writing, 17(2), 102-118. https://doi.org/10.1016/j.jslw.2007.11.004

Bruton, A. (2009). Designing research into the effect of error correction in $\mathrm{L}_{2}$ writing: not so straightforward. Journal of Second Language Writing, 18(2), 136-140. https://doi.org/10.1016/j.jslw.2009.02.005

Crossley, S. A., \& Mc Namara, D. S. (2009). Computational assessment of lexical differences in $\mathrm{L}_{1}$ and $\mathrm{L}_{2}$ writing. Journal of Second Language Writing, 18, 119-135. https://doi.org/10.1016/j.jslw.2009.02.002

De Graaff, R. (1997). The experanto experiment: Effects of explicit instruction on second language acquisition. Studies in Second Language Acquisition, 17, 379-410. https://doi.org/10.1017/s0272263197002064

De la Fuente, M. (2009). The role of pedagogical task and focus on form in acquisition of discourse markers by advanced learners. In R. P. Leow, H. Campos, \& D. Lardiere (Eds.), Little words: Their history, phonology, syntax, semantics, pragmatics, and acquisition (pp. 211-221). Washington, DC: Georgetown University Press.

Dekeyser, R. (1995). Learning second language grammar rules: An experiment with a miniature linguistic system. Studies in Second Language Acquistion, 17, 379-410. https://doi.org/10.1017/S027226310001425X

Ellis, R. (2005). Principles of instructed language learning. System, 33(2), 209-224. https://doi.org/10.1016/j.system.2004.12.006

Ellis, R., \& Reinders, H. (2009). The effect of two types of input on intake and the acquisition of implicit and explicit knowledge. In R. Ellis, S. Loewen, C. Elder, R. Erlam, J. Philp, \& H. Reinders (Eds.), Implicit and explicit knowledge in second language learning, testing, and teaching (pp. 281-302). Bristol: Multilingual Matters.

Ellis, R., \& Sinclair, J. (2003). Intuition and annotation-the discussion continues. In K. Aijmer, \& B. Altenberg (Eds.), Language and computers. Paper presented at the 23rd International Conference on English Language Research on Computerized Corpora (ICAME 23). Goteborg.

Ellis, R., \& Yuan, F. (2004). The effects of planning on fluency, complexity and accuracy in second language narrative writing. Studies in Second Language Acquisition, 26, 59-84. https://doi.org/10.1017/S0272263104261034

Ellis, R., Sheen, Y., Murakami, M., \& Takashima, H. (2008). The effects of focused and unfocused written corrective feedback in English as a foreign language context. System, 36(3), 353-371. https://doi.org/10.1016/j.system.2008.02.001

Farley, A. (2004). Processing instruction aid the Spanish subjunctive: Is explicit information needed? In B. Vanpatten (Ed.), Processing instruction: theory, research, and commentary (pp. 227-239). Mahwah, NJ: Lawrence Erlbaum.

Ferris, D. (2010). Second language writing research and written corrective feedback in SLA. Studies in Second Language Acquisition, 32(2), 181-201. https://doi.org/10.1017/S0272263109990490

Flahive, D. E., \& Snow, B. G. (1980). Measures of syntactic complexity in evaluating ESL compositions. In J. Olier, \& Perkins (Eds.), Research in language testing (pp. 171-176). Rowley. MA: Newbury.

Fuller, J. M. (2003). The influence of speaker role on discourse markers use. Journal of Pragmatics, 35, 23-45. http://dx.doi.org/10.1016/so378-2166(02)00065-6

Gabrielatos, C. (2002). EFL Writing: Product and Process. Retrieved from http://www.gabrielatos.com/EFLWriting.htm

Gass, S. (1997). Input, interaction, and the second language learner. Mahwah, NJ: Erlbaum.

Hamp-lyons, L. (2002). The scope of writing assessment. Assessing Writing, 8(1), 5-16. https://doi.org/10.1016/S1075-2935(02)00029-6

Hatch, E., \& Wanger-Gough, J. (1976). Explaining sequence and variations in second language acquisition. Language Learning, 4, 39-47. 
Hernandez, T. A. (2008). The effect explicit instruction and input flood on students' use of discourse markers on a simulated oral proficiency interview. Hispania, 91, 665-675.

Hillocks, G. (2005). The focus on form versus content in teaching writing. Research in Teaching of English, 40(2), 238-248.

Perkins, M. R. (1983). Modal Expressions in English. London: Frances Printer.

Polio, C., Fleck, C., \& Leder, N. (1998). "If only I had more time”: ESL learners' changes in linguistic accuracy on essay revisions. Journal of Second Language Writing, 7(1), 43-68. https://doi.org/10.1016/S1060-3743(98)90005-4

Rahimi, M. (2011). Discourse markers in argumentative and exposing writing of Iranian EFL learners. World Journal of English Language, 1(2), 68-78. http://dx.doi.org/10.5430/wjel.v1n2p68

Richard, J. C., \& Schmidt, R. (Eds.). (2002). Longman dictionary of language teaching and applied linguistics (3rd ed.). London: Longman.

Robinson, P. (2003). Attention and memory during SLA. In C. J. Doughty, \& M. H. Long (Eds.), Handbook of second language acquisition (pp. 631-678). Oxford: Blackwell. https://doi.org/10.1002/9780470756492.ch19

Robinson, P. (2005). Cognitive complexity and task sequencing: studies in a componential framework for second language task design. International Review of Applied Linguistics, 43(1), 1-32. https://doi.org/10.1515/iral.2005.43.1.1

Rosa, E. E. \& O’Neill, M. (1999). Explicitness, intake, and the issue of awareness: Another piece to the puzzle. Studies in Second Language Acquisition, 21, 511-566. https://doi.org/10.1017/s0272263199004015

Schmidt, R. (1990). The role of consciousness in second language learning. Applied Linguistics, 11(2), 129-158. https://doi.org/10.1093/applin/11.2.129

Schmidt, R. (2001). Attention. In P. Robinson (Ed.), Cognition and Second Language Instruction (pp. 3-32). Cambridge: Cambridge University Press. https://doi.org/10.1017/CBO9781139524780.003

Sheen, Y. (2007). The effect of focused written corrective feedback and language aptitude on ESL learners' $\begin{array}{lllll}\text { acquisition } & \text { of } & \text { articles. }\end{array}$ https://doi.org/10.1002/j.1545-7249.2007.tb00059.x

Sheen, Y. (2010). Differential effects of oral and written corrective feedback is SLA: Theoretical bases. Studies in second language acquisition, 32(2), 169-179. https://doi.org/10.1017/S0272263109990489

Skehan, P. (1996). A framework for the implementation of task-based instruction. Applied Linguistics, 17, 38-62. https://doi.org/10.1093/applin/17.1.38

Skehan, P. (1998). A Cognitive approach to language learning. Oxford: Oxford University Press.

Skehan, P., \& Foster, P. (2001). Cognition and tasks. In P. Robinson (Ed.), Cognition and second language instruction (pp. 188-205). Cambridge: Cambridge University Press. https://doi.org/10.1017/CBO9781139524780.009

Taguchi, N. (2009). Pragmatic competence. Deutsche Nationalbibliothek. https://doi.org/10.1515/9783110218558

Trahey, M., \& White, L. (1993). Positive evidence and preemption in the second language classroom. Studies in Second Language Acquisition, 15, 181-204. https://doi.org/10.1017/S0272263100011955

Truscott, J. (1996). The case against grammar correction in $\mathrm{L}_{2}$ writing classes. Language Learning, 46(2), 327-369. https://doi.org/10.1111/j.1467-1770.1996.tb01238.x

Truscott, J. (2004). Evidence and conjecture on the effects of correction: A response to chandler. Journal of Second Language Writing, 13(4), 337-343. https://doi.org/10.1016/j.jslw.2004.05.002

Wendel, J. (1997). Planning a second language narrative production. Unpublished

White, J. (1998). Getting the learner' attention: A typographical input enhancement study. In C. Doughty, \& J. Williams (Eds.), Focus on form in classroom: Second language acquisition (pp. 85-113). Cambridge: Cambridge University Press.

Williams, J., \& Evans, J. (1998). What kind of focus and which form? In C. Doughty, \& J. Williams (Eds.), Focus on form in classroom second language acquisition (pp. 139-155). Cambridge: Cambridge University 
Press.

Wolfe-Quintero, K., Inagaki, S., \& Kim, H. (1998). Second language development in writing: Measures of fluency, accuracy, and complexity. Manoa, HI: Second Language Teaching and Curriculum Center, University of Hawaii.

Wong, W. (2004). Processing instruction in French: The roles of explicit information and structured input. In B. VanPatten (Ed.), Processing instruction: Theory, research, and commentary (pp. 187-205). Mahwah, NJ: Lawrence Erlbaum.

Yoshimi, D. R. (2001). Explicit instruction and JFL learners use of interactional discourse markers. In K. Rose, \& G. Kasper (Eds.), Pragmatics in language teaching (pp. 223-244). Cambridge: Cambridge University Press. https://doi.org/10.1017/CBO9781139524797.016

Young, L. (1994). University lectures - marco-structure and micro-features. In J. Flowerdew (Ed.), Academic listening: Research perspectives (pp. 159-176). Cambridge: Cambridge University Press.

\title{
Appendix A
}

\author{
Accuracy (ratio) $=\frac{\text { Number of correct connectors }- \text { number of wrong connectors }}{\text { Number of words }}$
}

\section{Copyrights}

Copyright for this article is retained by the author(s), with first publication rights granted to the journal.

This is an open-access article distributed under the terms and conditions of the Creative Commons Attribution license (http://creativecommons.org/licenses/by/4.0/). 